\begin{tabular}{|c|c|c|}
\hline ITC 4/46 & \multicolumn{2}{|c|}{$\begin{array}{c}\text { Macroscopic Geographical Speed of Data Transmission in } \\
\text { European Internet }\end{array}$} \\
\hline $\begin{array}{l}\text { Vol. } 46 / \text { No. } 4 / 2017 \\
\text { pp. } 521-529\end{array}$ & Received 2016/08/23 & Accepted after revision $2017 / 10 / 31$ \\
\hline $\begin{array}{l}\text { DOI 10.5755/j01.itc.46.4.16113 } \\
\text { (๑) Kaunas University of Technology }\end{array}$ & \multicolumn{2}{|c|}{ Crossef http://dx.doi.org/10.5755/j01.itc.46.4.16113 } \\
\hline
\end{tabular}

\title{
Macroscopic Geographical Speed of Data Transmission in European Internet
}

\section{Dan Komosny}

Brno University of Technology, Department of Telecommunications, Technicka 12, 61600 Brno, Czech Republic e-mail:komosny@feec.vutbr.cz

\section{Miralem Mehic}

University of Sarajevo, Department of Telecommunications, Zmaja od Bosne bb, Kampus Univerziteta, 71000 Sarajevo, Bosnia and Herzegovina, e-mail: miralem.mehic@etf.unsa.ba

\section{Miroslav Voznak}

VSB-TU Ostrava, Department of Telecommunications, 17. listopadu 15/2172, 70833 Ostrava, Czech Republic miroslav.voznak@vsb.cz

Corresponding author: komosny@feec.vutbr.cz

The paper deals with the geographical speed of IP data transmission in the European Internet. We measure the geographical speed using a large set of PlanetLab servers with known physical location. Based on the results we propose a method to identify the maximum geographical distance that data can travel in Europe for given communication latency. A more accurate estimation of the geographical distance between the Internet nodes helps to improve location-aware Internet services and applications. We show that the method results in smaller delimited areas of possible node locations.

KEYWORDS: Internet, distance, speed, latency, measurement, PlanetLab, location, geolocation.

\section{Introduction}

This paper deals with measurement of the Internet geographical aspects. Fundamental research into geographical aspects of the Internet is encouraged by a large variety of Internet services and applications. Some of the common services are peer-to-peer networks, distributed storage, emergency services, and 
social networks $[20,2,6]$. The Internet geographical aspects are also used in cybersecurity to block or detect the source of the attacks. This is particularly needed when specific providers or countries do not cooperate to render the intrusion [17, 23]. In this paper, we identify the theoretical and real maximal geographical distance that Internet data can travel for given communication latency in Europe. We base our findings on observation of the patterns of the formed latency/distance pairs. We apply a grouping Mean-shift algorithm to form clusters of such pairs. The position of the clusters shows almost a linear dependence of latency on geographical distance up to $2000 \mathrm{~km}$, which is approximately one half of the cumulated geographical size of the European countries from west Portugal to east Ukraine.

We demonstrate the use of the findings by improving IP geolocation. IP geolocation finds a geographical location of a node by its IP address remotely and it is independent of the device type (server, desktop, mobile), its software (operating system, installed applications), and its connection type (fixed cable, WiFi, cellular) [7, 24].

The paper is organized as follows: Section 2 gives an overview of the current approaches to evaluate the geographical aspects of the global Internet. It specifically focuses on the relationship between communication latency and geographical distance. Section 3 describes the measurement system used for this research. The global testbed, PlanetLab, is described along with the source of the locations used. Section 4 covers an analysis of the data measured. We describe the clustering algorithm used and introduce the findings. Section 5 demonstrates the use of the findings. It describes IP geolocation and shows its performance improvement. Section 6 summarizes the paper.

\section{Related Work}

We first describe related measurement systems of the macroscopic Internet. Next, we focus on the particular studies and their related results.

There are several approaches and projects dealing with measurement of the macroscopic Internet. They focus on different aspects of the global Internet, primarily on the performance of data transmission (routing, delay, and bandwidth) and the communication structure (physical and logical).

The global measurement infrastructure DIMES [21] was developed to derive time-related snapshots of the Internet performance from different points of view, such as interconnection of the autonomous systems and router geographical/logical distribution. Mainly communication delay and data loss is investigated. The DIMES agents are distributed over the whole world and they are run by volunteers who also provide the geographical location of the agents. The agents are run voluntary and their number changes in time. This complicates the repetition of the measurements over long periods of time.

The European Internet Measurement Infrastructure ETOMIC [18] provides pan-European traffic measurement testbed with the GPS-equipped agents. The GPS technology provides precise location information for each agent. It also guarantees time-sensitive delay measurements. The time-sensitivity is also provided by a dedicated network interface used. Researchers can upload their developed measurement software to the agents. This allows the creation of the specific per-measurement scenarios.

Archipelago [3] is global measurement infrastructure run by CAIDA (Center for Applied Internet Data Analysis). Its aim is to provide community-oriented Internet measurement infrastructure that allows users to run their measurement projects. Archipelago also runs the measuring agents worldwide. Some agents are built on the nowadays popular Raspberry Pi platform. One of the key features is the parallel processing that allows obtaining measurement results from all world /24-size routed networks in 2-3 days.

PlanetLab [26, 22] is a network of Linux servers distributed over the whole world. It is an open system allowing researchers to run their code on standard Linux machines. We use this global network as the base for our research and we give further details about PlanetLab in Section 3. We also describe the developed measurement system in this section.

The related macroscopic Internet geographical aspects have been studied in the following papers:

Matray et al. [16] studied the geographic layout of the Internet, specifically the spatial properties of its topology and data routing. They show that the Internet paths do not coincide with the shortest geographical paths. The link circuitousness in Europe was around 40\%. The logical/geographical path stretch was above 1.5. The most significant dispersion in path stretching was observed for distances below $2000 \mathrm{~km}$. The routing symmetry was also studied. This particularly 
unveiled the similarity between the direct and return path. The result was that more than $80 \%$ of the paths could be considered as symmetrical.

Krajsa and Fojtova [15] studied the dependence of round-trip latency (RTT) on geographical distance. They observed the world-wide relationship of latency and distance. A detailed analysis of communication within continents showed that the median RTT values for transmissions originated and ended within Europe had a linear dependence on distance approximately up to $3000 \mathrm{~km}$. We relate these values to our results by observing a linear latency on distance dependence up to $2000 \mathrm{~km}$.

Kasiviswanathan et al. [10] studied the geographical aspects of the Internet. The measurements were focused on the global US and particular US states. The authors observed an interesting coast-to-coast shuttling of the Internet traffic even when the source and destination were geographically close to each other. They concluded that the interconnection (peering) between the autonomous networks was almost geographically independent. The authors confirmed that the short geographic distances had larger logical path stretch. Paths with direct long geometrical distances over $3000 \mathrm{~km}$ had an average stretch around 1.8.

\section{Measurement System}

The used macroscopic Internet measurement system is based on a real network of Linux servers. The servers are a part of PlanetLab that is a global network focusing on the Internet services research and development [12]. The clusters of the measuring servers are shown in Figure 1. The cluster labels show the number of servers in each cluster. We considered more than 350 servers in Europe at more than 200 different places. The servers run a number of Linux operating systems in separated virtual environments. A new virtual environment is created for each project. Each virtual environment is remotely accessible using SSH. This allows to upload and run the developed applications and collect the results.

The location of the servers is required to evaluate the Internet geographical aspects. We obtained the locations through the PlanetLab interface, where information about each server is available. However, we observed that some locations provided were incorrect

\section{Figure 1}

Clusters of PlanetLab servers

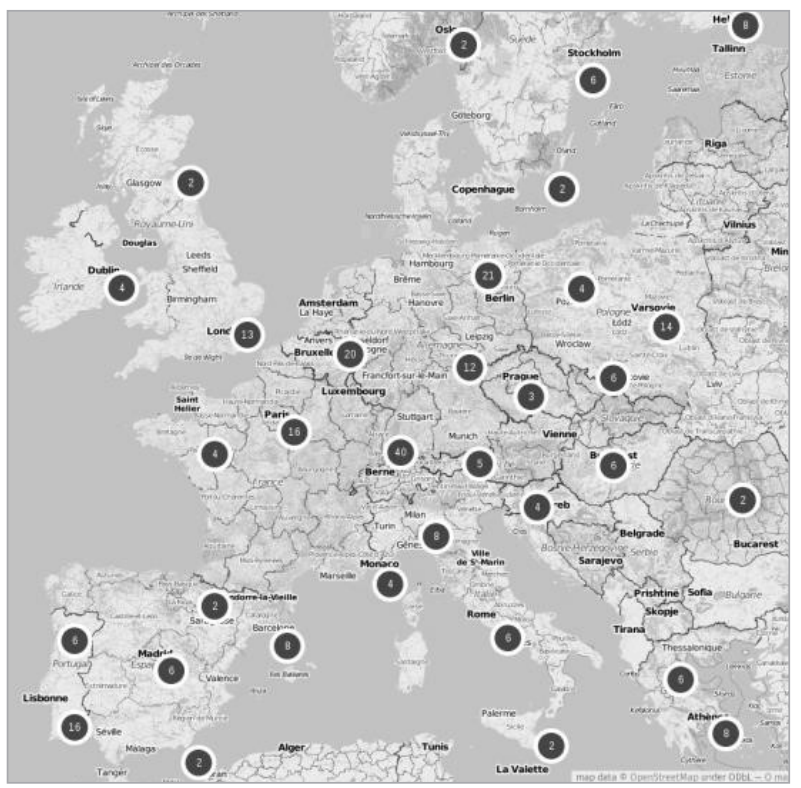

as they pointed to areas outside the cities where the nodes were claimed to be. We improved the accuracy of the provided locations by comparing the server coordinates with the corresponding results from IP geolocation databases [9]. We also compared the server coordinates to the postal addresses of the organizations running the servers [13].

Figure 2 shows an overview of the information flow in the developed measuring system. The measurement application was uploaded to the PlanetLab servers. This application was developed in $\mathrm{C}++$ and statically compiled to solve the problem of differences between the Linux virtual environments on the servers, such

\section{Figure 2}

An overview of the measurement system

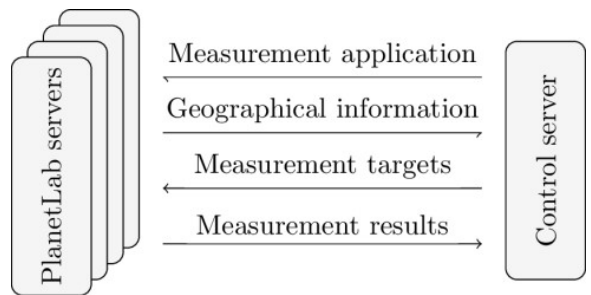


as 32 and 64-bit versions of the kernel, and the lack of some libraries. The next information distributed to the PlanetLab servers was a list of the measurement targets (servers to which the measurements were done). As both lists of the servers were changing in time, we automatically updated the lists each day. The measurement results were reported to the control server immediately after each measurement. The measurements where processed using a number of applications developed in Python. We mainly based the applications on the Pandas and GeoPandas Python modules that allow processing of large datasets.

\section{Identification of Geographical Speed of the Internet}

\subsection{Measured Data Analysis}

During a three-month measurement, we obtained approximately four million data items. The application run on the control server initiated the particular measurements at specific times to cover all day hours and all week days. The measurement hours were evenly distributed within each day. This way we ensured that the data measured cover all the hour/week combinations of the Internet traffic including the morning and afternoon peaks during the week days and, also including the reduced traffic during night times or during the weekends.

Table 1 shows the measured data details and their relation to geographical distance. The mean and median latency are of similar values -22 and $21 \mathrm{~ms}$, respectively. The specific quartile values show that the distribution of latency values is almost uniform. The average distance between the measuring servers is around

Table 1

Geographical speed of Internet data transmission

\begin{tabular}{l|c|c|c} 
& Latency $[\mathrm{ms}]$ & Distance $[\mathrm{km}]$ & Speed $[\mathrm{km} / \mathrm{ms}]$ \\
\hline Mean & 22.08 & 1206 & 55.98 \\
\hline Std. dev. & 11.53 & 705 & 18.89 \\
\hline 1st q. & 13.85 & 659 & 43.15 \\
\hline Median & 21.05 & 1120 & 56.18 \\
\hline 3rd q. & 28.45 & 1624 & 68.28
\end{tabular}

$1200 \mathrm{~km}$. The difference between the mean and median distances is around $1000 \mathrm{~km}$. The correlation factor of latency and distance is $\mathrm{r}=0.8057$ with the linear model equal to $\mathrm{y}[\mathrm{km}]=49.23 \mathrm{x}[\mathrm{ms}]+119.2 \mathrm{~km}$. The mean and median geographical speed of data transmission are also of similar values around $56 \mathrm{~km} / \mathrm{ms}$. As we used the shortest great-circle paths between the measurement servers, these speeds are lower than the speed of signal transmission in optical cables, which is the typical transmission medium for longer distances in the Internet. The speed of signal transmission in optical cables is $2 / 3$ of the speed of light in a vacuum, which is about $200 \mathrm{~km} / \mathrm{ms}$ [11]. Applying the findings presented in the related work about the logical/geographical path stretch factor to be around 2 for the medium and longer distances, we can double the measured speed to obtain an average (and also median) value of $110 \mathrm{~km} /$ $\mathrm{ms}$. Still we are far from the theoretical value $(200 \mathrm{~km} /$ $\mathrm{ms}$ ). The difference between these values is due to additional delays caused by data processing on the path. This is mainly the time needed for packet routing. Other devices on the path, such as switches, also prolong the time of data transmission [8].

\subsection{Theoretical Maximum Speed}

We identify the theoretical maximum geographical speed of Internet data transmission as the highest ratio of all the maximal distance/minimal latency measured pairs. The highest ratio found was for the latency of $3.72 \mathrm{~ms}$ at the distance of $451 \mathrm{~km}$, giving the theoretical speed equal to $121.28 \mathrm{~km} / \mathrm{ms}$. These values were measured from a node in the Czech Republic at the coordinates (latitude, longitude) 50.102 and 14.3916 (Prague) to a node in Hungary at the coordinates 47.4726 and 19.0597 (Budapest). The details of this maximum speed path are shown in Table 2. The table also shows the number of the routers on the path (hops), the source/destination node names, the names of the routers on the path and their geographical locations. The geographical locations were obtained via two sources as indicated in the table. For the source and destination devices we used the coordinates provided by PlanetLab (shown as PLB). The locations of the routers were obtained from a geolocation database that stores location information for IP addresses of the Internet devices [9, 5]. We used the location database IP2Location (shown as IP2L). This database particularly gives the correct locations of the routers belonging to the pan-European network geant.net. 


\section{Table 2}

Maximum speed path. The source of location information: PLB - PlanetLab, IP2L - IP2Location. The coordinates are rounded

\begin{tabular}{ll|c|c}
\multicolumn{1}{c|}{ Hop DNS/IP } & Lat, Lon & Loc. source \\
\hline 0 planetlab3.cesnet.cz & $50.10,14.39$ & PLB \\
\hline 1 r112-gw.cesnet.cz & $50.09,14.42$ & IP2L \\
\hline 2 cesnet.mx1.pra.cz.geant.net & $50.09,14.42$ & IP2L \\
\hline $3 \quad 62.40 .98 .50$ & $47.50,19.04$ & IP2L \\
\hline 4 hungarnet- & $47.50,19.04$ & IP2L \\
\hline 5 tgo-1-0-0.rtr.bme.hbone.hu & $47.50,19.04$ & IP2L \\
\hline 6 xge2-1.taz.net.bme.hu & $47.48,19.07$ & IP2L \\
\hline 7 xge4-1.styx.net.bme.hu & $47.48,19.07$ & IP2L \\
\hline 8 xger7-1.ixion.net.bme.hu & $47.48,19.07$ & IP2L \\
\hline 9 tmitgw.tmit.bme.hu & $47.48,19.07$ & IP2L \\
\hline 10 planetlab2.tmit.bme.hu & $47.47,19.06$ & PLB \\
\hline
\end{tabular}

The related work shows that the logical links experience some level of circuitousness. Higher values are observed for shorter geographical distances and lower values are observed for medium to longer distances. Inspecting the location of the routers on this maximum speed path, we observed that it has a very low circuitousness and thus reaching the speed of 121.28 $\mathrm{km} / \mathrm{ms}$. Figure 3 shows the measured geographical distance dependence on communication latency. The line 'Typical distance' shows an interpolation of the latency values. The line 'Absolute maximum distance'

\section{Figure 3}

Theoretical maximum and typical geographical distance for measured communication latency

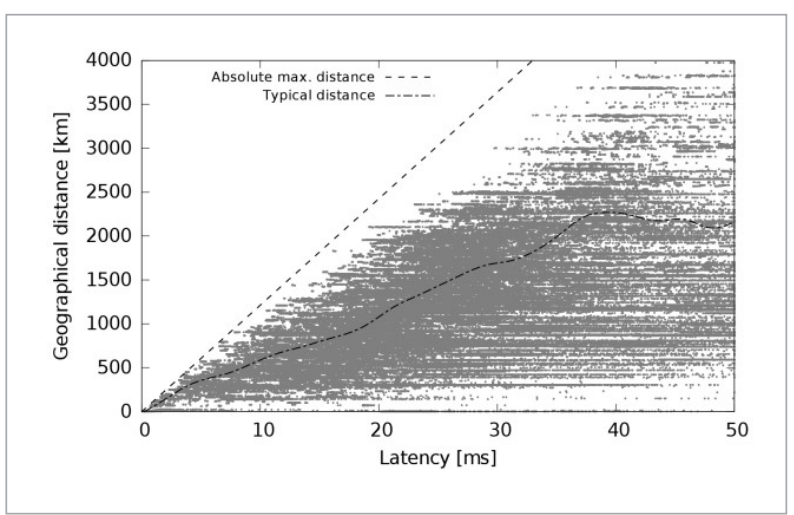

shows the maximum distance that data can travel for a communication latency. The line is based on the identified theoretical maximum speed.

\subsection{Real Maximum Speed}

The maximum distance that data can travel for a communication latency does not correspond with the distribution of the other maximum distance/minimum latency pairs as shown in Figure 3. We therefore identify the real speed of the Internet data transmission to follow the actual distribution of the distance/latency pairs. We approach this by defining an envelope consisting only of the maximum distance/minimum latency pairs as shown in Figure 4. The envelope distance/latency pairs are grouped into sets. These sets are formed at specific distances and the range of minimum latencies is increasing with higher distances. In the figure, an example set is highlighted by a circle. The centre of each set is approximately linearly dependent on the latency.

To confirm these observations, we applied a clustering algorithm to group the latencies into appropriate clusters and find the centre of each cluster. For this purpose, we considered several clustering algorithms based on the following criteria: i) the number of clusters is not known in advance, ii) the cluster size is uneven, iii) the clustering metric is the distance between the pairs. We found a suitable clustering algorithm to be Mean-shift [4]. This algorithm works with the smooth density of the pairs to discover the clusters.

The result after applying the Mean-shift algorithm upon the envelope is shown in Figure 5. Each centre of

\section{Figure 4}

An envelope created from measured pair sets

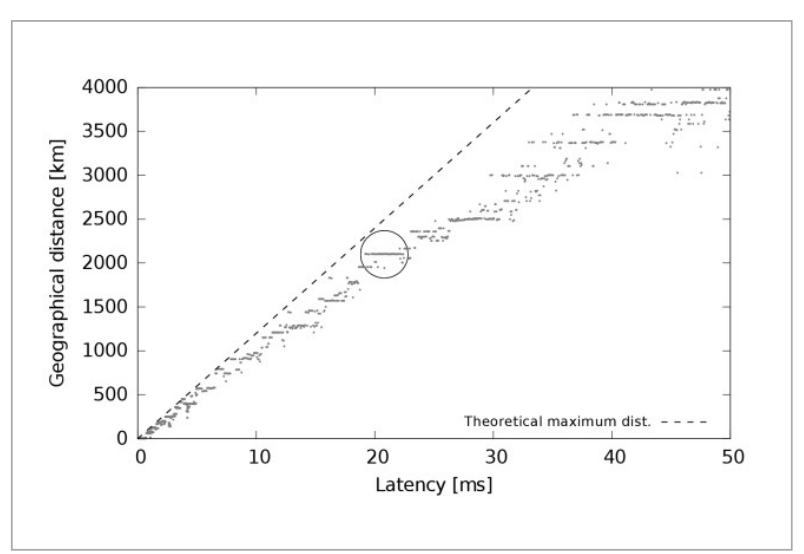




\section{Figure 5}

Identified clusters and their centres

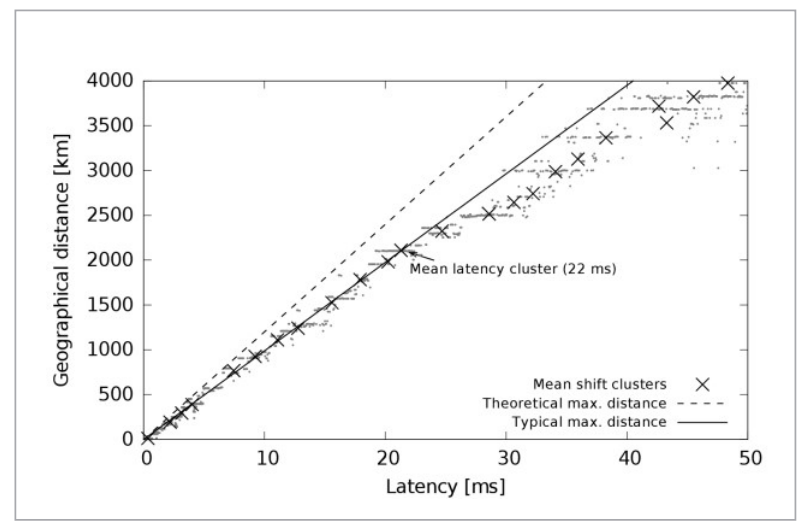

the formed clusters is indicated with a cross. As suggested, the distances given by the cluster centres are almost linearly dependent on the latencies up to the cluster containing a latency of $22 \mathrm{~ms}$ at the distance around $2000 \mathrm{~km}$. The clusters above this distance do not follow the linear increase pattern. This is probably caused by packet processing on a greater number of routers on longer paths. Each router diffuses the communication latencies, which is in the figure indicated by a greater range of latencies for higher distances. A linear interpolation of the cluster centres gives the real maximum speed of data transmission in the Internet equal to $98.76 \mathrm{~km} / \mathrm{ms}$.

\section{IP Geolocation Improvement}

There are various algorithms for measurement-based IP geolocation $[25,1,19]$. These algorithms typically work with the detection of the maximum geographical distance between Internet nodes using latency measurements. The latency is measured from a set of servers (landmarks) with known geographical location to the node located. The latencies measured are converted to maximum geographical distances from each server to the node located. These distances form the great-circles around each landmark. The place of the node located is given by the area delimited by the intersection of the great-circles. It is a common problem that the great-circles might not intersect. This is caused by incorrect latency-to-distance conversion [14]. The delimited area is further processed to re- strict the possible node locations. Typically, the major city in the area or the centre-of-gravity of the area is used as shown in Figure 6. Other common approaches focus on the application of geographical constraints, such as excluding the countryside or seas/lakes [25], or using other resources, such as finding the closest web server in the area to the node located [24].

\section{Figure 6}

Delimited polygon and its centre-of-gravity

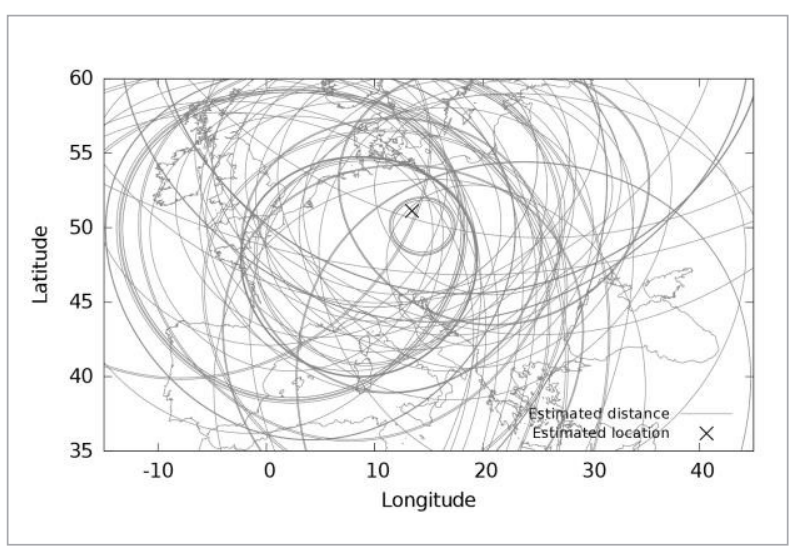

We applied the speed of data transmission to reduce the size of the delimited area of a node location. We also tested that the reduction does not produce wrong great-circle intersections (underestimations). We particularly modified the latency-to-distance conversion to estimate the maximum distance between the landmarks with known location and the node located. In order to verify the results, we used an IP geolocation system working in Europe. We geolocated a set of groundtruth nodes and compared the results with their correct locations. The groundtruth nodes and their correct locations were obtained by scanning the open WiFi networks using a mobile application. This application runs on smartphones and links the smartphone public IP address to its current location taken from the in-built GPS device. We used 583 groundtruth nodes in 15 European countries, distributed in 65 regions, and in 260 cities.

Only the delimited areas below a certain size were considered. Some of the estimated areas were so large that they covered nearly whole Europe and therefore they were not usable for geolocation. We therefore used a maximum size of the delimited polygon area of 
650 thousand km² (approx. size of France). Areas with greater sizes are excluded from the results.

The geolocation system works with the PlanetLab servers that act as the landmarks with known geographical location. These servers are distributed over Europe. We faced a problem that their number changed during particular measurements as some of them became online or went off-line. We therefore present two sets of results. The first set shows the results when all the currently available (on-line) landmarks were used. Their number varied with the average of 50 landmarks. The second set shows the results with the selected 30 fixed landmarks that were found always on-line during all the measurements. The placement of these landmarks is shown in Figure 7. They were located in these cities: Barcelona, Prague, Pamplona, Karlsruhe, Turin, Freiburg, Wroclaw, Troyes, Tampere, Targu Mures, Munich, Strasbourg, Naples, Oslo, Kaiserslautern, Vigo, Hamburg, Oulu, Warsaw, Rome, Zurich, and Moscow (there were two servers in some cities).

\section{Figure 7}

The location of 30 selected fixed landmarks

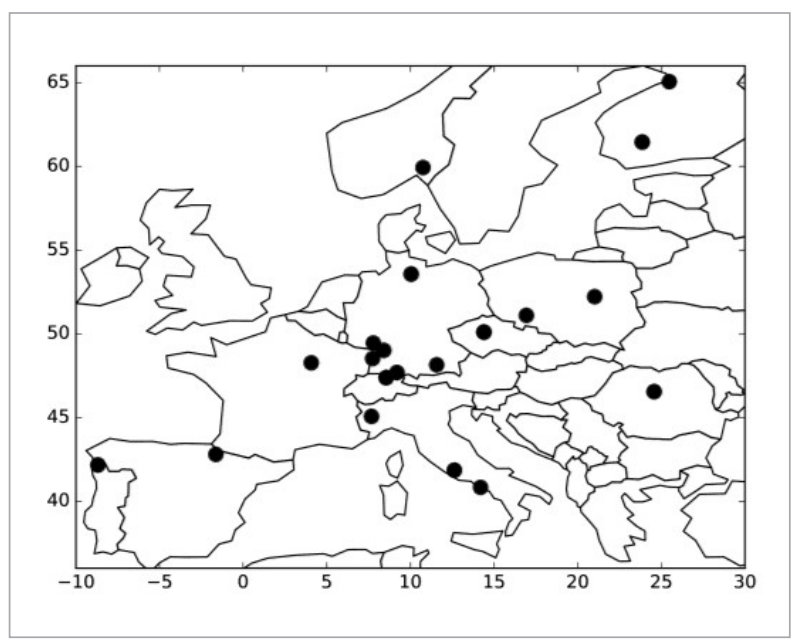

The results are shown in Figure 8. It shows the cumulative probability of the size of the delimited polygons. Only areas below the limit of $650,000 \mathrm{~km}^{2}$ are plotted. All the areas covered the correct groundtruth location. Any incorrect great-circle intersection occurred during area identification. The probabilities show that an improvement is reached when the real maximum speed of Internet data transmission is used. This is true for both sets of landmarks - all the currently available (average 50) and the selected always on-line (fixed 30).

\section{Figure 8}

Reduction of valid geolocated area below upper limit of $650,000 \mathrm{~km}^{2}$

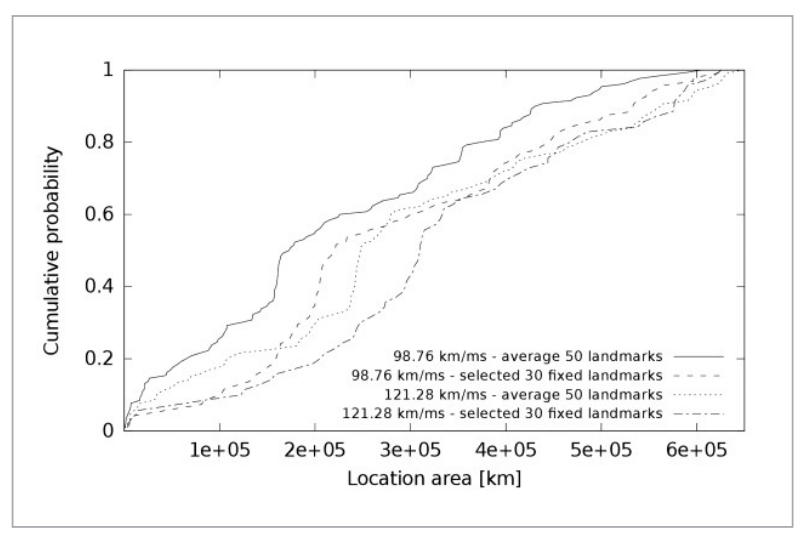

The details of delimited areas are shown in Table 3 for the theoretical speed of $121.28 \mathrm{~km} / \mathrm{ms}$ and in Table 4 for the real speed of $98.76 \mathrm{~km} / \mathrm{ms}$. Again, the results are shown for the two sets of landmarks. The tables show the percentage of the estimated valid areas i.e. areas below the upper limit of $650,000 \mathrm{~km}^{2}$. The number of the valid areas was increased by approx. $10 \%$ when the real maximum speed was used for both sets of landmarks. The median of the area size was reduced by $74,000 \mathrm{~km}^{2}$ for all currently available landmarks.

\section{Table 3}

Valid geolocated area below upper limit of $650,000 \mathrm{~km}^{2}$ for speed $121.28 \mathrm{~km} / \mathrm{ms}$ [thousand $\mathrm{km}^{2}$ ]

\begin{tabular}{c|c|c|c|c}
\hline Landmarks & Valid [\%] & Mean & Median & $\begin{array}{c}\text { Std. } \\
\text { dev. }\end{array}$ \\
\hline All (average 50) & 46 & 292 & 248 & 182 \\
\hline Select. (fixed 30) & 32 & 330 & 310 & 160 \\
\hline
\end{tabular}

\section{Table 4}

Valid geolocated area below upper limit of $650,000 \mathrm{~km}^{2}$ for speed $98.76 \mathrm{~km} / \mathrm{ms}$ [thousand $\mathrm{km}^{2}$

\begin{tabular}{c|c|c|c|c}
\hline Landmarks & Valid [\%] & Mean & Median & $\begin{array}{c}\text { Std. } \\
\text { dev. }\end{array}$ \\
\hline All (average 50) & 56 & 221 & 173 & 158 \\
\hline Select. (fixed 30) & 43 & 285 & 221 & 161 \\
\hline
\end{tabular}




\section{Conclusions}

We found the theoretical maximum geographical speed of data transmission in the European Internet to be $121.28 \mathrm{~km} / \mathrm{ms}$. However, this speed does not follow the distribution of all the measured distance/ latency pairs. Based on the pairs clustering, the real geographical speed of Internet data transmission in Europe was identified to be $98.76 \mathrm{~km} / \mathrm{ms}$.

\section{References}

1. Arif, M. J., Karunasekera, S., Kulkarni, S. GeoWeight: Internet Host Geolocation Based on a Probability Model for Latency Measurements. In Proceedings of the 33rd Australasian Conference on Computer Science, Australian Computer Society, Inc., 2010, 102, 89-98.

2. Bo, H., Cook, P., Baldwin, T. Geolocation Prediction in Social Media Data by Finding Location Indicative Words. In Proceedings of the 24th International Conference on Computational Linguistics (COLING 2012), 2012, 1045-1062.

3. Claffy, K. The 7th Workshop on Active Internet Measurements (AIMS7) Report. ACM SIGCOMM Computer Communication Review, 2016, 46(1), 50-57. https:// doi.org/10.1145/2875951.2875960

4. Comaniciu, D., Meer, P. Mean Shift: A Robust Approach Toward Feature Space Analysis. IEEE Transactions on Pattern Analysis and Machine Intelligence, 2002, 24(5), 603-619. https://doi.org/10.1109/34.1000236

5. Freedman, M., Vutukuru, M., Feamster, N., Balakrishnan, H. Geographic Locality of IP Prefixes. In Proceedings of the 5th ACM SIGCOMM Conference on Internet Measurement (IMC'05), USENIX, 2005, 153-158. https://doi.org/10.1145/1330107.1330124

6. Graham, M., Hale, S., Gaffney D. Where in the World Are You? Geolocation and Language Identification in Twitter. The Professional Geographer, 2014, 66(4), 568-578. https://doi.org/10.1080/00330124.2014.907699

7. Gueye, B., Ziviani, A., Crovella, M., Fdida, S. Constraint-Based Geolocation of Internet Hosts. IEEE/ ACM Transactions on Networking, 2006, 14(6), 12191232. https://doi.org/10.1109/TNET.2006.886332

8. Hegr, T., Bohac, L., Kocur, Z., Voznak, M., Chlumsky, P. Methodology of the Direct Measurement of the Switching Latency. Przeglad Elektrotechniczny, 2013, 89(7), 59-63.

9. Huffaker, B., Fomenkov, M., Claffy, K. Geocompare: A Comparison of Public and Commercial Geolocation
We applied the results to improve measurementbased IP geolocation by a reduction of the delimited area of a node location. For this purpose, a European geolocation system was used. Also, a set of groundtruth nodes with known correct locations was used to validate the correctness of IP geolocation. The results showed a $10 \%$ increase of the number of valid areas to be used for geolocation. The median of the delimited area size of a node location was reduced by $74,000 \mathrm{~km}^{2}$.

Databases. Technical Report, Cooperative Association for Internet Data Analysis (CAIDA), 2011.

10. Kasiviswanathan, S., Eidenbenz, S., Yan, G. Geography-Based Structural Analysis of the Internet. In 2010 Internet Measurement Conference, ACM, 2010, 1-9.

11. Katz-Bassett, E., John, P., Krishnamurthy, A., Wetherall, D., Anderson, T., Chawathe, Y. Towards IP Geolocation Using Delay and Topology Measurements. In Proceedings of the 6th ACM SIGCOMM Conference on Internet Measurement, 2006, 71-84. https://doi. org/10.1145/1177080.1177090

12. Komosny, D., Pang, S., Pruzinsky, J., Ilko, P., Polasek, J. PlanetLab Europe as Geographically-Distributed Testbed for Software Development and Evaluation. Advances in Electrical and Electronic Engineering, 2015, 13(2), 137-146. https://doi.org/10.15598/aeee.v13i2.1245

13. Komosny, D., Pruzinsky, J., Ilko, P., Polasek, J., Masek, P., Kocatepe, O. On Geographic Coordinates of PlanetLab Europe. In IEEE, 38th International Conference on Telecommunications and Signal Processing (TSP), 2015, 642-646. https://doi.org/10.1109/ TSP.2015.7296342

14. Komosny, D., Voznak, M., Kathiravelu, G., Sathu, H. Estimation of Internet Node Location by Latency Measurements - The Underestimation Problem. Information Technology and Control, 2015, 44(3), 279-286. https:// doi.org/10.5755/j01.itc.44.3.8353

15. Krajsa, O., Fojtova, L. RTT Measurement and Its Dependence on the Real Geographical Distance. In IEEE, 34th International Conference on Telecommunications and Signal Processing, 2011, 231-234. https://doi. org/10.1109/TSP.2011.6043737

16. Matray, P., Haga, P., Laki, S., Csabai, I., Vattay, G. On the Network Geography of the Internet. In IEEE Proceedings INFOCOM, 2011, 126-130. https://doi.org/10.1109/ INFCOM.2011.5934909 
17. MaxMind. Fraud Detection through IP Address Reputation and a Mutual Collaboration Network. White Paper, 2011.

18. Morato, D., Magana, E., Izal, M., Aracil, J., Naranjo, F., Astiz, F., Alonso, U., Csabai, I., Haga, P., Simon, G., Steger, J., Vattay, G. The European Traffic Observatory Measurement Infraestructure (ETOMIC): A Testbed for Universal Active and Passive Measurements. In IEEE, Testbeds and Research Infrastructures for the DEvelopment of NeTworks and COMmunities (TRIDENTCOM 2005), 2005, 283-289.

19. Moravek, P., Komosny, D., Burget, R., Sveda, J., Handl, T., Jarosova, L. Study and Performance of Localization Methods in IP Based Networks: Vivaldi Algorithm. Journal of Network and Computer Applications, 2011, 34(1), 351-367. https://doi.org/10.1016/j. jnca.2010.06.014

20. National Emergency Number Association (NENA). VoIP Location WG. NENA Technical Requirements Document (TRD) for Location Information to Support IP-Based Emergency Services. NENA 08-752, Issue 1, 2006.

21. Shavitt, Y., Shir, E. DIMES: Let the Internet Measure Itself. ACM SIGCOMM Computer Commu- nication Review, 2005, 35(5), 71-74. https://doi. org/10.1145/1096536.1096546

22. Verespej, H., Pasquale, J. A Characterization of Node Uptime Distributions in the PlanetLab Test Bed. In 30th IEEE Symposium on Reliable Distributed Systems (SRDS), 2011, 203-208. https://doi.org/10.1109/ SRDS.2011.32

23. Voznak, M., Safarik, J., Rezac, F. Threat Prevention and Intrusion Detection in VoIP Infrastructures. International Journal of Mathematics and Computers in Simulation, 2013, 7(1), 69-76.

24. Wang, Y., Burgener, D., Flores, M., Kuzmanovic, A., Huang, C. Towards Streetlevel Client-Independent IP Geolocation. In 8th USENIX Conference on Networked Systems Design and Implementation, 2011, 365-379.

25. Wong, B., Stoyanov, I., Sirer, E. Octant: A Comprehensive Framework for the Geolocalization of Internet Hosts. In Proceedings of the 4th USENIX Conference on Networked Systems Design \& Implementation, USENIX Association, 2007, 313-326.

26. Wonho, K., Ajay, R., Li, K., Pai, V. Understanding and Characterizing PlanetLab Resource Usage for Federated Network Testbeds. In Proceedings of ACM Internet Measurement Conference (IMC), 2011, 515-532.

\section{Summary / Santrauka}

The paper deals with the geographical speed of IP data transmission in the European Internet. We measure the geographical speed using a large set of PlanetLab servers with known physical location. Based on the results we propose a method to identify the maximum geographical distance that data can travel in Europe for given communication latency. A more accurate estimation of the geographical distance between the Internet nodes helps to improve location-aware Internet services and applications. We show that the method results in smaller delimited areas of possible node locations..

Straipsnyje rašoma apie geografinį Europoje naudojamo interneto ryšio IP duomenų perdavimo greiti. Autoriai matuoja geografinį greitį, naudodami didelį PlanetLab serverių komplektą su žinoma fizine buvimo vieta. Remiantis rezultatais, siūlomas metodas, skirtas identifikuoti maksimalų geografinį atstumą, kuriuo duomenys gali keliauti Europoje, įskaitant komunikacijos laiko uždelsimą. Tikslesnis geografinio atstumo tarp interneto mazguc įvertinimas padeda patobulinti buvimo vietą žinančias internetines paslaugas ir programèles. Autorių siūlomas metodas padeda aptikti mažesnes, neapribotas galimas mazgų buvimo vietas. 